\title{
Impact of Energy Efficient Construction Details on Seismic Resistance of Passive Buildings
}

\author{
[ Vojko KILAR, Boris AZINOVIĆ and David KOREN ]
}

\begin{abstract}
Recently, an increasing trend of passive and lowenergy buildings transferring from non-earthquake prone to earthquake-prone regions has thrown out the question about the seismic safety of such buildings. The paper describes two most commonly used structural details of energy efficient construction, which could be critical from the point of view of earthquake resistance: i) Foundation of a building on thermal insulation (TI) layers and ii) Fixing of precast balcony element without thermal bridge. The first part of the paper describes the problematics of founding of a building on TI and presents the authors' proposal of seismic fuse assembled out of TI boards and waterproofing (foil) layers, which have been commonly used under the $\mathrm{RC}$ foundation slabs of passive buildings. The main idea is to reduce the seismic forces on the superstructure by allowing controlled lateral sliding between the individual layers of the TI boards. The feasibility of the proposed solution has been analysed by means of nonlinear dynamic analyses for selected 2- and 4-storeyed passive buildings founded on TI boards made of extruded polystyrene (XPS). The second part of the paper analyses the seismic response of precast balcony cantilever structural elements, which have been recently developed in seismic non-prone areas in order to prevent the thermal bridge at the point where the cantilever is fixed to the building. Such balcony elements have been made primarily to withstand vertical static loading neglecting the eventual vertical seismic loads in the case of an earthquake. It has been found out that those cantilevers in the case of uplift might not be designed with adequate safety, since they lack sufficient reinforcement on the bottom side. In order to reduce their seismic vulnerability some changes of precast load-bearing TI elements have been proposed.
\end{abstract}

Keywords-earthquake response, extruded polystyrene (XPS), foundations on thermal insulation layer, low-energy buildings, seismic analysis, thermal bridge, cantilever structures, precast elements

\section{Introduction}

The requirement that buildings should be constructed without any thermal bridges is a trend, which applies to most newly built buildings in cold climate areas. For this reason, attempts are frequently made to resolve the question of problematic joints by the insertion of thermally insulating parts between the load-bearing structural elements. This can cause weakening of the structure in the most crucial parts of the building, thus threatening its stability and integrity. In this paper, selected energy efficient construction details are investigated from the point of view of seismic resistance (Fig. 1). An extensive description and schematic representation of other building structural details that might

Vojko KILAR, Boris AZINOVIĆ and David KOREN

University of Ljubljana, Faculty of Architecture

Slovenia be critical from the point of view of earthquake resistance can be found in [1]. It has been therefore suggested, that the suitability of such details and technical solutions should be first verified from the viewpoint of their earthquake resistance before they are used in buildings in earthquakeprone areas.

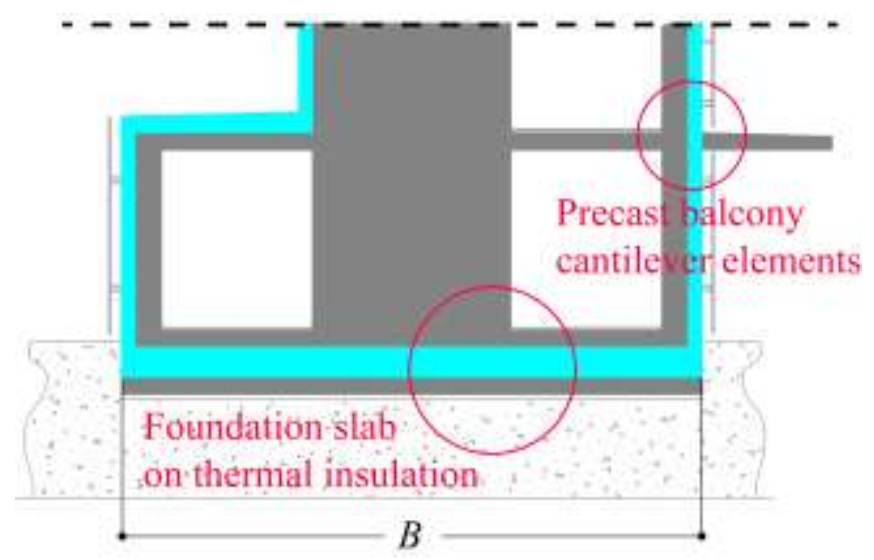

Figure 1. Schematic representation of two selected critical energy.

\section{Foundation on Thermal Insulation Layers}

The most frequently used technique for preventing a thermal bridge beneath the ground floor slab is founding of the building on TI layer(s), which need to have adequate compressive strength. Extruded polystyrene (XPS) boards, expanded polystyrene (EPS) boards, and boards made of cellular glass are most frequently used for this purpose. They are usually placed under the reinforced concrete (RC) foundation slab or under the strip foundations in one or more layers. From the point of view of earthquake resistance, it should be pointed out that, by inserting the flexible layers of TI between the reinforced concrete (RC) foundation slab and the layer of blinding concrete on the ground, the fundamental period of the structure would be prolonged. The fundamental periods are increased by rocking effects, which are a consequence of the vertical deformability of the insulation layer as well as by shear deformability of TI. Most passive houses are low-rise buildings with short fundamental periods which could be elongated by the insertion of a TI layer, and thus moved into the resonance part of the design response spectrum. In such cases the expected top accelerations of the structure could increase by a factor of two or three in comparison with a structure on a fixed base. Such an increase could lead to damage to the superstructure or its content, which should not be ignored [1-7]. However, if the fundamental period of the superstructure is already on the plateau of constant accelerations, the insertion of TI under the foundation slab might prolong the structural period into the descending 
branch, so that the seismic forces acting on the structure might be reduced. Only in this case will the TI layer act as a traditional seismic base isolation system [8-14], so that the earthquake induced forces would be reduced.

\section{A. Research and the Proposed Foundation Detail}

In the first stage of the research, the cyclic material characteristics of the XPS foam, which is one of the most frequently used material for TI under foundations, have been tested for the first time. The cyclic compressive and shear stress-strain behaviour of XPS foam obtained by experiments can be found in $[4,7,15,16]$. In the same reference the sliding resistance of the individual surfaces located between the layers of the thermally insulated construction sets was also studied.

In the second stage of the research the seismic behaviour of buildings founded on deformable TI layers have been analysed. The preliminary results of simplified studies on the seismic response of buildings with an XPS layer beneath the (rigid) foundation slab have been presented in [2]. The main assumption of this study was that the upper building was modelled as a rigid block resting on elastic foundations and the stress control in the XPS layer under foundation slab was made by simplified seismic analysis based on the equivalent horizontal forces method. It was shown that, in general, the seismic safety of passive houses with heights of up to 2 or 3 storeys is not of critical concern. In continuation of our research [3] the upper structure was idealized by a single degree of freedom nonlinear system with a stiff foundation slab lying on an XPS layer modelled by a set of vertical and horizontal nonlinear springs. The analysed buildings were assumed to be founded on very stiff soils, so that soil-structure interaction (SSI) effects were not taken into account. It was concluded that amplifications of selected observed response parameters can be expected in the case of stiffer buildings with higher strength ratios. The amplifications, as might be expected, in general increase with the number of storeys, the slenderness of the building, and the seismic weight of the building. On the other hand, in the case of more flexible structures a positive effect due to a reduction in the superstructure ductility demand was detected. Recently, the seismic response of an actual multistoreyed RC frame (wall) building founded on an RC foundation slab has been analysed [7]. In this reference the superstructure was modelled by a complete 2D MultipleDegree-of-Freedom (MDOF) lumped plasticity frame model (with rigid links) that enables to track the development of damage induced by insertion of a soft TI layer beneath the foundation slab. The SSI effects including different soil types have been also considered.

The obtained results showed that the use of TI beneath the foundation slab of a superstructure generally induces a higher structural peak response compared to the system where there is no TI beneath the foundation slab. These response amplifications could be substantial and might result in the exceedance of the structural or TI layer capacity values. For this reason, a new technological solution for reducing the seismic response of passive houses founded on layers of TI boards has been recently proposed by the authors $[5,7]$. The reduction of the seismic forces which are induced on the superstructure was achieved by allowing controlled lateral sliding to occur along the horizontal surface between the individual layers of the TI boards, as a kind of seismic fuse. The solution has been developed on the basis of existing passive house foundation details, which were designed in order to prevent the occurrence of thermal bridges running from the heated interior of the building to the ground underneath. The proposed solution still permits the use of existing foundation construction details, while its added value consists of the additional components for the controlled response of buildings in seismically active areas, taking advantage of the sliding effect. The additional components are shown in Fig. 2, and are marked as follows; (1) vertical restrainers for the prevention of uncontrolled rocking and larger lateral shifts, (2) a lateral sliding gap $(\Delta H)$, (3) the imposed sliding surface, and (4) horizontal stoppers for the prevention of sliding at the contact surface between the blinding concrete and the first layer of TI. The proposed solution is protected by a patent that has been filed at the Slovenian Intellectual Property Office (SIPO). The principle of the solution is analogous to that of sliding seismic base isolation systems [8-13].

\section{Foundation floor plan}

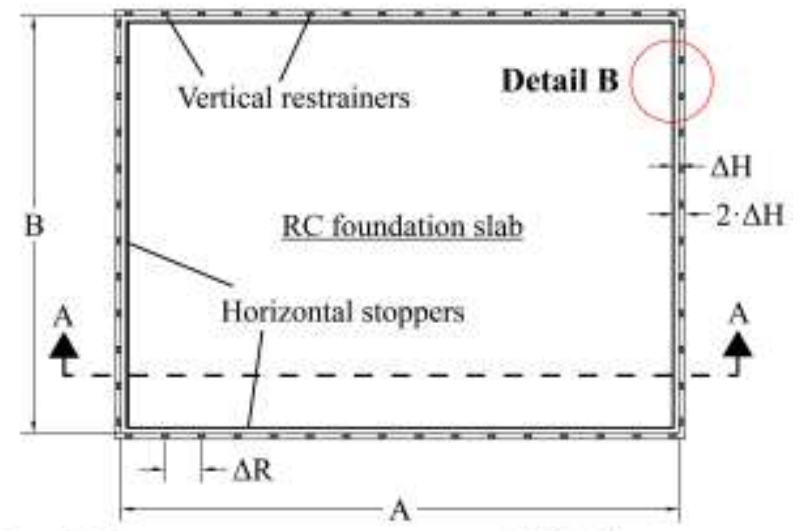

Detail B

-initial state (undeformed)

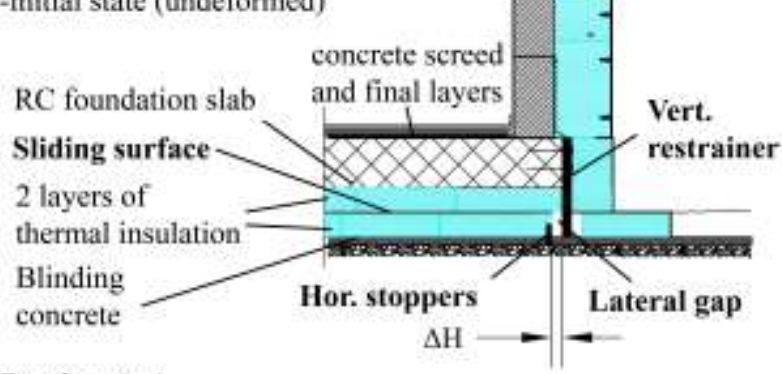

Section A-A

-sliding mode
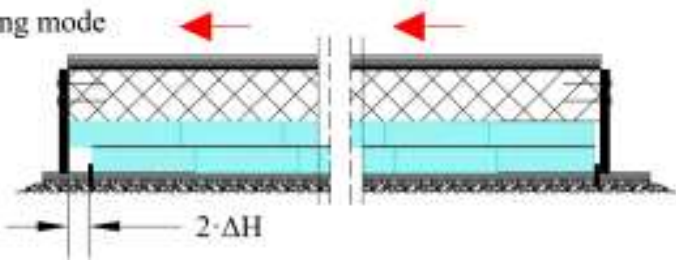

Figure 2. Schematic representation of the proposed solution with the included anti seismic sliding components.

\section{B. Selected Results}

The applicability of the proposed solution has been demonstrated by means of the nonlinear dynamic analysis of some simplified parametric models, as well as of some realistic models of two, four and six storeyed RC passive 
house buildings [5, 7]. The effect of different friction coefficients was analysed, as well as their influence on the structural behaviour. Depending on the size of the friction coefficient acting at the horizontal surface between the individual layers of the TI boards, three different seismic response scenarios can be foreseen: Scenario 1: Basic protection ("sliding prevention"), Scenario 2: Extended protection ("sliding controllable"), and Scenario 3: Full protection ("sliding isolation system"). The results showed that the total base shear that might act on the superstructure could be reduced by permitting sliding between the layers of TI boards, thus reducing or even preventing the occurrence of damage. In the case of Scenario 2 the proposed seismic fuse could be used in modern energy-efficient houses practically without any additional costs.

In Fig. 3 the selected results of the simplified (SDOF) model for the analysed 2-storeyed building are presented in the form of mean incremental dynamic analysis (IDA) curves while in Fig. 4 the obtained damage patterns of the 4storeyed model of an actual RC building founded on foundation sets with different friction coefficients $(\mu)$ are presented, together with the absolute maximum base $\left(D_{\text {base }}\right)$ and top displacements $\left(D_{\text {top }}\right)$ as well as the maximum compressive deformations of the XPS layer ( $\left.\varepsilon_{\mathrm{XPS}}\right)$. The results indicate significant changes in the response depending on the different friction coefficients $(\mu)$. It should be noted that in the case of models with lower $\mu$ values large sliding displacement $\left(D_{\text {base }}\right)$ occur and thus, a particular attention will need to be given to the design of flexible installations, the seismic gap clearance, and auxiliary recentering devices in order to make sure that the sliding isolation will be effective. In Fig. 3, the green lines $(\mu=$ $0.10)$ and the black lines $(\mu=0.90)$ represent two extreme scenarios, one for a sliding isolation system and the other for sliding prevention. The results confirm the validity of the assumption that models with high $\mu$ values $(\mu=0.90)$ result in the lowest values of $D_{\text {base }}$ and the highest ductility demands for the superstructure. On the other hand, the results for $\mu=0.10$ yielded the highest values of $D_{\text {base }}$ and the lowest ductility demands for the superstructure among all the compared friction variations.

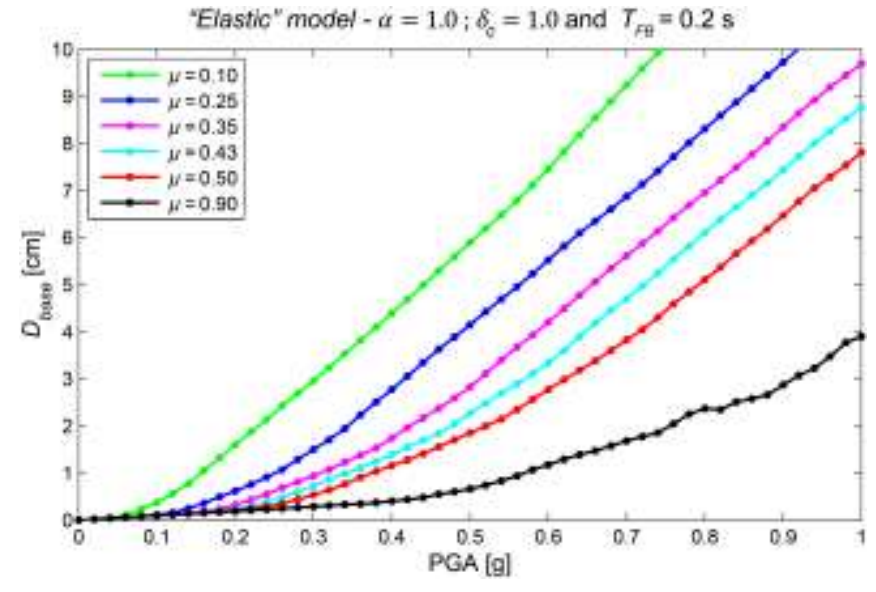

Figure 3. Mean IDA curves of the maximum base displacement $\left(D_{\text {base }}\right)$ for the elastic SDOF models.

In the case of the analysed model of an actual building (Fig. 4) it should be noticed that the superstructure remains elastic when friction coefficients $\mu=0.10$ was applied. Thus, in the case of the design PGA level $(0.25 \mathrm{~g})$, a friction coefficient $\mu=0.10$ could be used if the third seismic response scenario (i.e. a sliding isolation system) were to be used. At PGA $=0.25 \mathrm{~g}$ the second scenario was reached when a friction coefficient of up to approx. $\mu=0.35$ was selected, while for larger values of $\mu$ the first seismic response scenario of sliding prevention is expected, and might result in partial or even global collapse mechanisms. It should be noted that the response of slender frames with large height-to-width ratios (e.g. the analysed 6-storeyed frame [5]) is governed strongly by the rocking mode of oscillation, which is evident from the presented average values of the maximum edge compressive deformations of the XPS ( $\left.\varepsilon_{\text {XPS }}\right)$. As can be seen from the obtained values the sliding isolation system successfully protects the superstructure against a rocking mechanism, since, in the case of the 4-storeyed frame, $\varepsilon_{\text {XPS }}$ decreases from $1.3 \%$ (sliding prevention) to $0.7 \%$ (sliding isolation system) of the thickness of the XPS layer $(d)$.

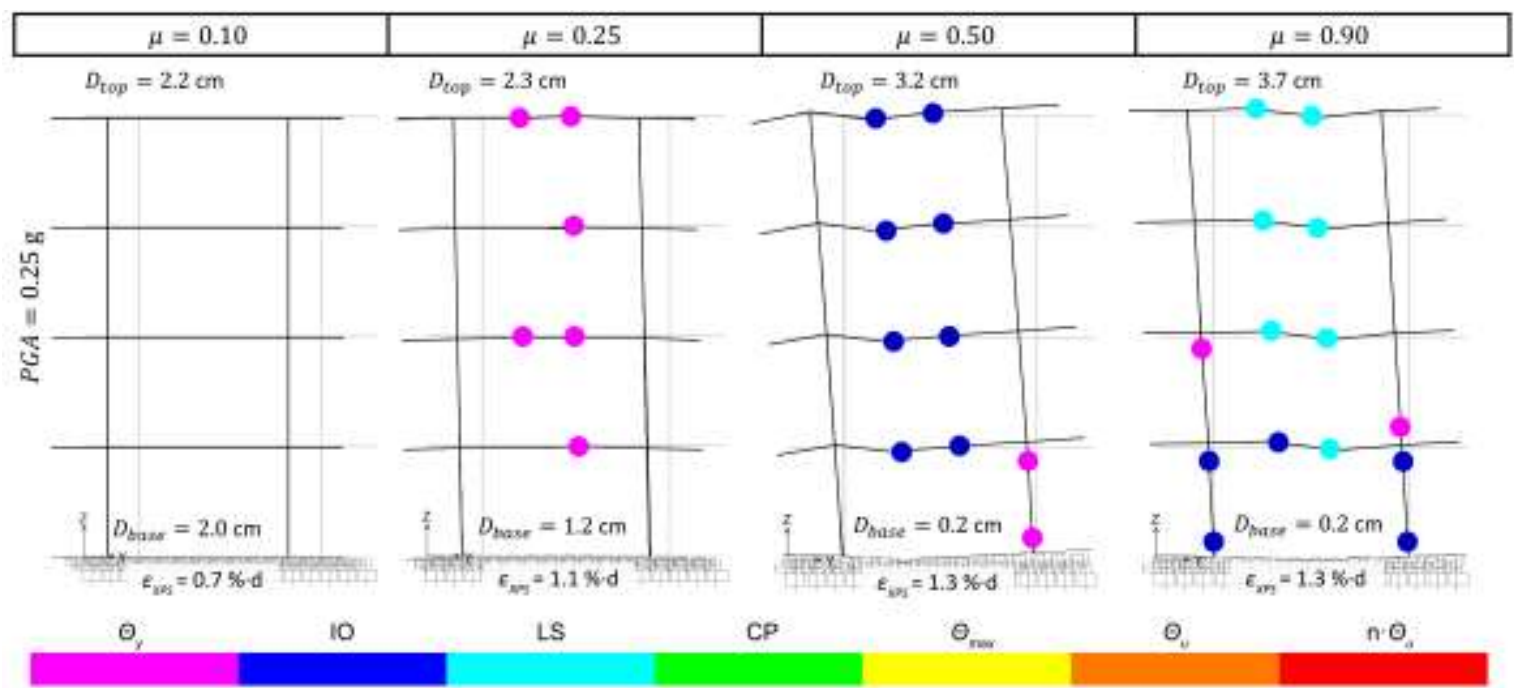

* The deformed shapes of the structures are presented (not to scale) for the last analysis step of a typical GMR.

Figure 4. Typical damage patterns and average maximum displacements of the analysed 4-storeyed RC structure (MDOF model) subjected to $0.25 \mathrm{~g}$. 


\section{Precast Balcony Cantilever Elements}

In the case of preventing thermal bridges between the balcony cantilever and the internal slab (Fig. 1), special innovative solutions of different load bearing TI elements were proposed by manufacturers of construction products. These products are experimentally tested on vertical gravity loads and their results are published by manufacturers in forms of different material for building designers. Some research [17], which compares the experimental and analytical results, was obtained with an intention to present a variety of potentially dangerous failure mechanisms of such load bearing TI elements exposed to vertical loads

When exposed to seismic shaking other critical issues could emerge. In the case of long cantilever the induced vertical oscillating could result in the local failure of the load bearing TI element. Moreover, such a detail can also be of critical concern for the global structural seismic response in the case when it interrupts the load bearing shear wall or column. In this case the structural vertical integrity is affected and could result in the deteriorated overall structural response. The models considered in the presented study were regular, straight RC cantilevers with constant cross-sections and without additional supports, such as beams, cables etc. To this date, there is no relevant literature investigating the seismic response of such elements, although they are one of the basic components of energyefficient buildings, which effectively prevent thermal bridges for balcony cantilevers. The solution proposed by most of the precast elements manufacturers is designed to disconnect the load-bearing structure, which exposes high thermal conductivity, and replace it with thermal insulation. Most widely used TI in such precast elements is expanded polystyrene (EPS) with thickness between 6-12 cm. The solution is extremely effective from the thermal performance point of view. However, it is more vulnerable to structural failure, since the weakening of the structure is positioned exactly at the cross-section with highest internal forces. The latter can be illustrated by a strength comparison of EPS, whose nominal compressive strength is usually lower than $200 \mathrm{kPa}$, and concrete C30/37, which exposes up to 100 times greater strength. Due to such strength difference, the manufacturers of precast elements additionally strengthen these elements by adding compressive bearings, which are placed at the bottom of the precast cross-section. These compressive bearings in most cases consist of micro-steel fibre reinforced highperformance concrete and also of synthetic polymers reinforced with fiberglass. The transfer of forces due to the negative internal moment is achieved by (stainless) steel tensile reinforcement on upper side of the cross-section and by compressive bearings at the bottom. In the paper, an agreement that negative moment causes tensile stress on the top edge of the cross-section is considered. In addition to compressive bearings, which also provide some shear resistance, reinforcing bars inclined at an angle of $45^{\circ}$ are used for the transmission of shear loads (Fig. 5). The results of numerous seismic analyses performed by the authors can be found in [18] and can be summarized as follows (Fig. 5): 1) the insertion of a precast load-bearing thermal insulation element increases the flexibility of RC fixed base cantilevers and therefore limits their length to $300-400 \mathrm{~cm}, 2$ ) vertical seismic loads can result in the cantilever uplift, which means that tensile stresses could appear also at the bottom of the cross-section 3) precast elements, that appear on the European market to this day, do not have the appropriate steel reinforcement in the bottom part of the cross-section. For this reason, the possibility of damage is considerably higher for precast cantilever structural elements than for RC fixed base cantilevers. One of the possible solutions to prevent the negative influences of cantilever uplift is to consider the proper reinforcement also at the bottom of the precast elements' cross-section, or by other measures preventing uplift.

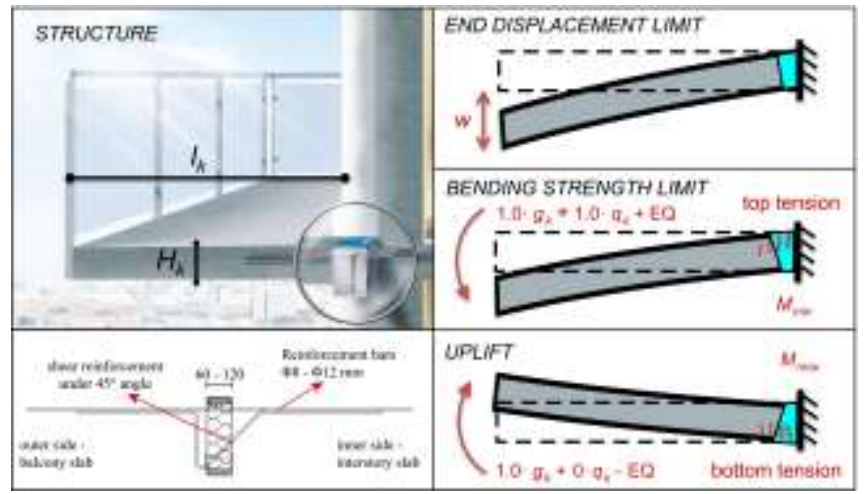

Figure 5. Thermally insulated RC cantilevers (TIC) model representation with corresponding labels and possible critical states.

In Fig. 6, the maximum internal moment at the cantilever fixed end is presented. The results are divided by negative moment resistance for each of the individual models $\left(M_{\mathrm{Rd}}\right)$ and are shown as a function of cantilever length and different seismic intensity. Cantilever uplift in the event of earthquakes is defined by the occurrence of positive internal moment at its fixed end. Uplift is therefore possible if earthquake load acts in the opposite direction of gravity and decreases vertical static loads effect (self-weight and dead loads).

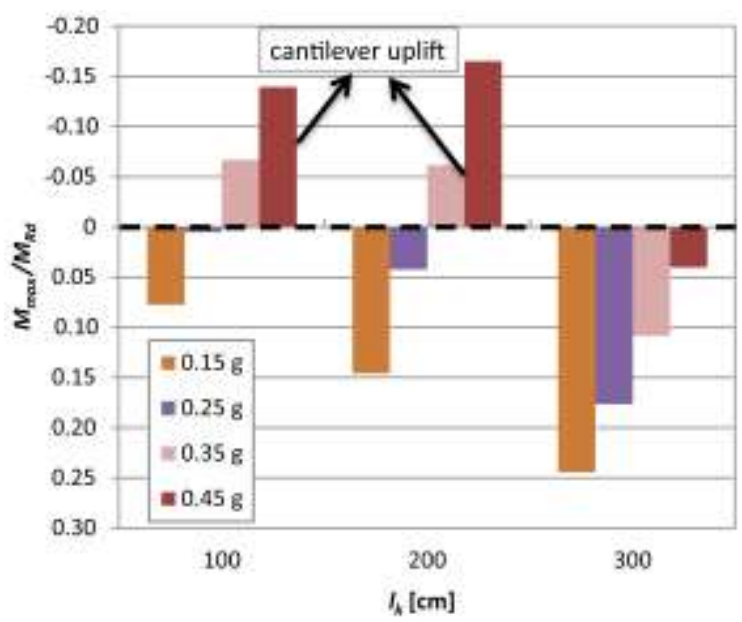

Figure 6. Maximum bending moment $\left(M_{\max }\right)$ due to the earthquake load dependent on the earthquake intensity (TIC models with no variable load, $\left.q_{\mathrm{k}}=0\right)$.

The bar graphs in Fig. 6, which are above the horizontal dashed line, indicate positive internal moment and uplift respectively. From the results shown, it can be concluded that the uplift phenomenon is more critical in the case of lightly loaded and short cantilevers, since positive internal moment appeared only for models shorter than $200 \mathrm{~cm}$. For 
cantilevers shorter than $100 \mathrm{~cm}$, uplift appeared already for seismic intensity of $0.25 \mathrm{~g}$, while for longer models higher seismic intensities were necessary to cause uplift. Thus, a certain level of seismic risk for cantilever damage due to the occurrence of uplift exists. In general TIC elements do not have tension reinforcement in the bottom part of the crosssection. This means that in the case of tensile stresses at the bottom of the cross-section, the compressive bearings, which expose negligible tensile strength, will be damaged. To avoid such damage, additional safety measures are necessary (e.g. the selection of improved load-bearing TI precast elements). A development of load-bearing TI elements should in the future be continued also in the direction of improving their seismic resistance. Some attempts to include additional tension reinforcement at the bottom of the precast elements can already be found in the latest catalogues of manufacturer Schöck. Such seismic elements at least partially solve the problem of uplift

\section{Conclusions}

In the paper, two selected energy efficient construction details have been investigated from the point of view of seismic resistance: i) foundation on thermal insulation (TI) layers and ii) precast balcony cantilever elements.

The seismic response of various building models have shown that the potentially negative influences of inserting the TI under the buildings' foundation slab could be expected only for three or more story high-rise buildings subjected to severe earthquakes. Oppositely, for the friction coefficient demand it was demonstrated that the largest demands could be expected also in the case of low-rise and light-weight buildings, yet in the case of moderate earthquake occurrence. Additionally, a new energy-efficient solution for the foundation of passive houses in earthquake prone regions is proposed. The seismic analyses of the proposed solution have shown that the permission of sliding between TI boards by using low friction contact surfaces can significantly reduce or even eliminate damage to the superstructure, and thus act as a seismic fuse. The proposed seismic response scenarios (sliding prevention, sliding controllable, and the implementation of a sliding isolation system) were demonstrated by means of nonlinear dynamic analysis for a set of various passive house structures. Before actual implementation in practice, the analytical results presented in the paper should be verified for specific contact and friction materials with the aid of tests on shaking tables or other simulations and tests. We also assume that the development of new cost-effective materials with even lower friction coefficient than available now, might further favour the idea of using such low cost seismic fuse in general low-rise housing in earthquake prone regions.

The results of the seismic analysis of precast thermally insulated cantilever (TIC) structural elements indicate that the existing TIC details expose limited earthquake safety in comparison with conventional reinforced concrete (RC) fixed base cantilevers. To reduce the seismic vulnerability of TIC elements some changes of precast load-bearing TI elements are necessary - tensile reinforcement in the bottom part of the cross-section (half of the upper reinforcement) should be added.

\section{Acknowledgments}

The financial support of the Slovenian Research Agency (research project L5-4319: "Safety of passive houses subjected to earthquake" and research program P5-0068: "Sustainable planning for the quality living space") is hereby gratefully acknowledged.

\section{References}

[1] B. Azinović, D. Koren and V. Kilar, "Principles of energy efficient construction and their influence on the seismic resistance of lightweight buildings," Open Civil Engineering Journal, vol. 8, pp. 105116, 2014.

[2] V. Kilar, D. Koren and M. Zbašnik-Senegačnik, "Seismic behaviour of buildings founded on thermal insulation layer," Građevinar, vol. 65, pp. 423-433, June 2013.

[3] B. Azinović, D. Koren and V. Kilar, "The seismic response of lowenergy buildings founded on a thermal insulation layer - A parametric study," Engineering Structures, vol. 81, pp. 398-411, December 2014.

[4] V. Kilar, D. Koren and V. Bokan-Bosiljkov, "Evaluation of the performance of extruded polystyrene boards - implications for their application in earthquake engineering," Polymer Testing, vol. 40, pp. 234-244, December 2014.

[5] B. Azinović, V. Kilar and D. Koren, "Energy-efficient solution for the foundation of passive houses in earthquake-prone regions," Engineering Structures, vol. 112, pp. 133-145, April 2016.

[6] D. Koren and V. Kilar, "Seismic vulnerability of reinforced concrete building structures founded on an XPS layer," Earthquakes and Structures, An Int'l Journal, in press, 2016

[7] D. Koren, V. Kilar and B. Azinović, "Seismic aspects of the application of thermal insulation boards beneath the foundations of buildings," in Insulation Materials, A. Almusaed, Ed. Rijeka: Intech, 2016 , in press.

[8] F. Naeim and J.M. Kelly, Design of seismic isolated structures: from theory to practice. John Wiley \& Sons; 1999.

[9] C. Christopoulos, A. Filiatrault, and V. V. Bertero, Principles of passive supplemental damping and seismic isolation: IUSS Press, 2006.

[10] W.K. Hong and H.C. Kim, "Performance of a multi-story structure with a resilient-friction base isolation system," Computers \& Structures, vol. 82, pp. 2271-2283, October 2004.

[11] V.R. Panchal and R.S. Jangid, "Seismic response of structures with variable friction pendulum system," Journal of Earthquake Engineering, vol. 13, pp. 193-216, 2009.

[12] P.C. Polycarpou and P. Komodromos, "On poundings of a seismically isolated building with adjacent structures during strong earthquakes," Earthquake Engineering \& Structural Dynamics, vol. 39, pp. 933-940, July 2010

[13] L.L. Chung, P.S. Kao, C.Y. Yang, L.Y. Wu and H.M. Chen, "Optimal frictional coefficient of structural isolation system," Journal of Vibration and Control, vol. 21, pp. 525-538, February 2015.

[14] V. Kilar and D. Koren, "Seismic behaviour of asymmetric base isolated structures with various distributions of isolators," Engineering Structures, vol. 31, pp. 910-921, April 2009.

[15] V. Bokan-Bosiljkov, Report on the experimental tests to determine the behavior of FIBRAN XPS products: Compression and shear behaviour. Report no. FIBRAN-13/01, Faculty of civil and geodetic engineering, University of Ljubljana, 2013 (in Slovenian).

[16] V. Bokan-Bosiljkov, Report on the experimental tests to determine the behavior of FIBRAN XPS products: Friction characteristics between the layers of selected construction sets. Report no. FIBRAN-13/02, Faculty of civil and geodetic engineering, University of Ljubljana, 2013 (in Slovenian)

[17] T. Heidolf and R. Eligehausen, "Design concept for load bearing thermal insulation elements with compression shear bearings," BetonUnd Stahlbetonbau, vol. 108, pp. 179-187, March 2013.

[18] B. Azinović, V. Kilar and D. Koren, "Erdbebensicherheit vorgefertigter wärmegedämmter Stahlbeton-Konsolenelemente," Bauingenieur, vol. 10, pp. 489-499, October 2015. 